\title{
Dermatomyositis autoantibodies: how can we maximize utility?
}

\author{
Luqman Mushila Hodgkinson, Tiffany Tingshuen Wu, David Franklin Fiorentino^
}

Department of Dermatology, Stanford University School of Medicine, Redwood City, CA, USA

Contributions: (I) Conception and design: LM Hodgkinson, DF Fiorentino; (II) Administrative support: LM Hodgkinson, DF Fiorentino; (III) Provision of study materials or patients: DF Fiorentino; (IV) Collection and assembly of data: LM Hodgkinson, DF Fiorentino; (V) Data analysis and interpretation: LM Hodgkinson, DF Fiorentino; (VI) Manuscript writing: All authors; (VII) Final approval of manuscript: All authors.

Correspondence to: David Franklin Fiorentino, MD, PhD. Department of Dermatology, Stanford University School of Medicine, Redwood City, CA, USA. Email: fiorentino@stanford.edu.

\begin{abstract}
The past 15 years has seen significant advances in the characterization of myositis-specific autoantibodies (MSAs) and their associated phenotypes in patients with dermatomyositis (DM). As more careful studies are performed, it is clear that unique combinations of clinical and pathological phenotypes are associated with each MSA, despite the fact that there is considerable heterogeneity within antibody classes as well as overlap across the groups. Because risk for interstitial lung disease (ILD), internal malignancy, adverse disease trajectory, and, potentially response to therapy differ by DM MSA group, a deeper understanding of MSAs and validation and standardization of assays used for detection are critical for optimizing diagnosis and treatment. Like any test, the diagnostic sensitivity and specificity of assays for various MSAs is not perfect. Currently tests for MSAs are helpful at minimum for a clinician to assess relative risk or contribute to diagnosis and perhaps counsel the appropriate patient about what to expect. With international standardization and larger studies it is likely that more antibody tests will make their way into formal schemata for diagnosis and actionable risk assessment in DM. In this review, we summarize key considerations for interpreting the clinical and pathologic associations with MSA in DM and identify critical gaps in knowledge and practice that will maximize their clinical utility and utility for understanding disease pathogenesis.
\end{abstract}

Keywords: Dermatomyositis (DM); autoantibodies; immunoassay

Submitted Jul 07, 2020. Accepted for publication Dec 31, 2020.

doi: $10.21037 / \mathrm{atm}-20-5175$

View this article at: http://dx.doi.org/10.21037/atm-20-5175

Dermatomyositis (DM) is one of the idiopathic inflammatory myopathies (IIMs) whose classification has continued to evolve over time (1-4). A widely adopted classification system separates the IIMs into DM, overlap myositis including mainly antisynthetase syndrome, immune-mediated necrotizing myopathy, and inclusion body myositis $(1,5)$. Other classification systems include polymyositis as a separate entity, pure polymyositis becoming rarer as more becomes known about the IIMs (2).

For the clinician, one of the challenging aspects about
$\mathrm{DM}$ is its heterogeneity. This creates difficulty in diagnosis as well as assessing patient risk for organ involvement and associated, often occult, internal malignancy. Diagnostically, DM can be confused with other rheumatic disorders (e.g., systemic lupus erythematosus, mixed connective tissue disease, rheumatoid arthritis, cutaneous lupus erythematosus), inflammatory myopathies, and cutaneous eruptions (e.g., drug eruptions, photosensitive dermatoses, psoriasis, and others). In terms of end-organ disease, patients can have variable skin morbidity, musculoskeletal

^ ORCID: 0000-0001-7951-3674. 
involvement, and lung disease, and, more rarely, severe gastrointestinal (GI) involvement. In some cases, such as patients with rapidly progressive lung disease or GI vasculopathy, early diagnosis and aggressive therapy may be required to avert morbidity or death. Because $7-32 \%$ of DM patients have an associated internal malignancy which is often occult at DM onset, the clinician is left with a quandary regarding how aggressively to screen DM patients for cancer (6-9). Having markers that enhance diagnosis and early detection of adverse prognostic features would theoretically allow earlier actionable therapy and improved patient outcomes.

It is now recognized that DM is associated with an intriguing diversity of myositis-specific autoantibodies (MSAs) that often have characteristic associated systemic and cutaneous manifestations (10-17). These MSAs define subclasses of disease with each autoantibody having characteristic clinical associations, organ pathology, HLA associations, and microRNA profiles (18-22). The comprehensive nature of these associations has been the subject of several excellent reviews and will not be reviewed here $(3,10-12,14,15,17,23,24)$. Instead, we focus on defining the current limitations and contradictions that limit their clinical utility for optimizing patient care and performing translational research.

Studies often differ in the reported prevalence of MSAs and their association with particular clinical features. Possible explanations for this include variable patient inclusion criteria, demographics, and MSA detection assays. The only MSA included as part of the EULAR/ACR classification criteria is anti-Jo-1, mostly due to the fact that during development of these guidelines, and even in many places presently, testing for the other DM-associated MSA was not widely available (25-27). The lack of validated, widely available, and affordable assays for MSA detection is one of the major factors that has hampered the use of MSAs in devising classification criteria and in clinical decisionmaking. However, it is very likely that other MSAs will be useful in the diagnosis and classification of DM even in light of current limitations (28).

$\mathrm{DM}$ is heterogenous, and there is a great need for better tools for diagnosis and prognosis. MSAs may be good biologic classifiers and risk management tools, but there are shortcomings with MSAs that presently limit this. Developing evidence-based screening guidelines for patients with DM is a priority, as leading causes of death in these patients are interstitial lung disease (ILD) and cancer $(29,30)$. In one study, for example, 5 -year survival among
DM patients was only $65 \%$, with cause of death segregating according to MSA type: $37 \%$ of anti-MDA-5 patients died of ILD and $28 \%$ of anti-TIF- $1 \gamma /$ anti-TIF- $1 \alpha$ patients died of cancer (16).

\section{Current understanding of MSAs}

Myositis-specific antibodies can be detected in more than $60 \%$ of patients with myositis and it is likely for DM patients that number approaches $80-90 \%$ using appropriately sensitive assays (our unpublished data) $(18,31)$. The major MSAs associated with DM are anti-Mi-2, anti-MDA-5, anti-NXP-2, anti-TIF-1 $\gamma$, and anti-SAE-1/2 (Table 1) (32). In addition, eight anti-synthetase autoantibodies (ASAs) have been defined that, in some cases, can mimic features of DM. These antibodies are: anti-Jo-1 (anti-histidyl-tRNA synthetase), anti-PL-12 (anti-alanyl-tRNA synthetase), antiPL-7 (anti-threonyl-tRNA synthetase), anti-EJ (anti-glycyltRNA synthetase), anti-OJ (anti-isoleucyl-tRNA synthetase), anti-KS (anti-asparaginyl-tRNA synthetase), anti-Zo (antiphenylalanyl-tRNA synthetase), and anti-Ha/YRS (antityrosyl-tRNA synthetase) (Table 1) (33). There is controversy about whether all patients with anti-synthetase antibodies have their own syndrome, given that some have features of DM $(1,2)$. Anti-synthetase syndrome and DM may not be completely separate and evaluation of criteria is ongoing $(1,2,4)$. There are also a number of myositis-associated antibodies (MAAs) including anti-PM/Scl, anti-Ro52, and anti-U1RNP, antibodies which are not specific to IIMs $(5,34)$.

Discovery of the MSAs dates back to over 40 years ago, and there has been slow evolution of the concept that they define biologically relevant subgroups of the IIMs, including subgroups within DM. Anti-Jo-1 antibodies were discovered in 1980 and subsequently identified in $15-25 \%$ of polymyositis and DM patients $(35,36)$. Anti-Jo- 1 antibodies are highly specific for the anti-synthetase syndrome and, although preferentially seen in myositis, can rarely also be found in patients with other autoimmune disorders such as systemic lupus erythematosus, systemic sclerosis, or other diseases $(33,36)$. Anti-Mi-2 autoantibodies were found to be specific for DM in the 1980s after anti-Mi-2 autoantibodies were initially described in polymyositis and DM $(37,38)$. Anti-NXP-2 antibodies were first described in 1997 and were initially denoted anti-MJ antibodies (39-43). Anti-MDA-5 antibodies were discovered in 2005 and were originally called anti-CADM-140 antibodies given their association with clinically amyopathic dermatomyositis (CADM) (44). Anti-155/140 autoantibodies were discovered 
Table 1 Myositis-specific antibodies and associated clinical phenotypes

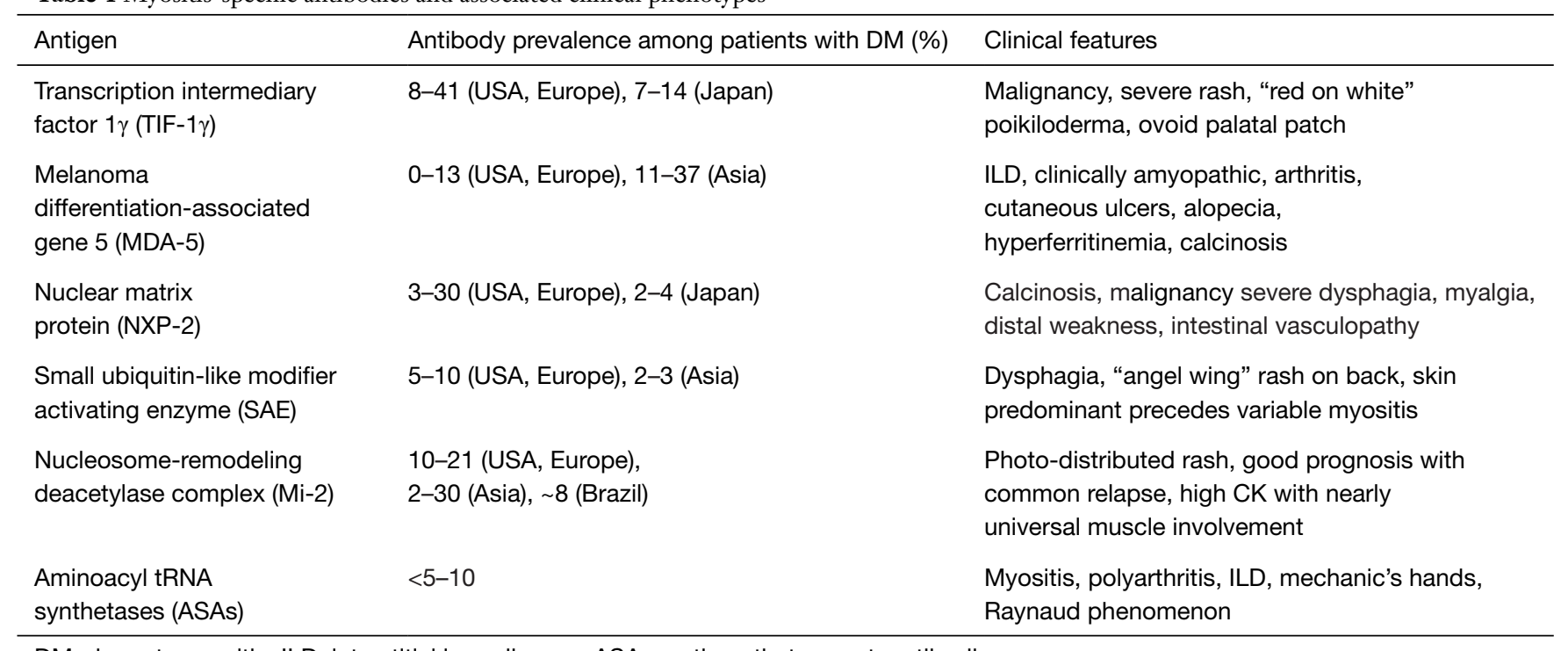

DM, dermatomyositis; ILD, interstitial lung disease; ASAs, anti-synthetase autoantibodies.

in 2007 and later shown to recognize TIF- $1 \gamma /$ anti-TIF$1 \alpha$ proteins, respectively, with TIF- $1 \beta$ being a target of antibodies much less frequently (45-47). In 2007, anti-SAE antibodies were reported, and appear to delineate another class of patients that otherwise would be seronegative for the known MSA (48).

The MSAs recognize diverse antigens and it has been challenging to identify a single theme that unites them with regards to cellular localization or function (Table 1). Mi-2 is part of the nucleosome-remodeling deacetylase complex which is involved in regulation of chromatin structure with effects on transcription and DNA repair as well as end-organ function, such as regulation of myoblast differentiation during muscle regeneration (49,50). MDA5 encodes a retinoic acid-inducible gene I (RIG-I)-like receptor that is a cytosolic double-stranded RNA sensor recognizing viral RNA for innate immunity (51). The nuclear matrix protein (NXP-2) has unclear function, but is known to have a role in 553 regulation $(39,52)$. TIF- $1 \gamma$, a member of the tripartite motif (TRIM) family of proteins that also includes TIF- $1 \alpha$ and TIF- $1 \beta$, has been shown to regulate transcription, tumor growth, DNA damage repair, and TGF- $\beta$ signaling $(45,47,53-56)$. SAE- $1 / 2$ are the A and B subunits of small ubiquitin-like modifier 1 (SUMO-1) activating enzyme, forming the heterodimer SAE that is involved in sumoylation, a post-translational process that regulates protein localization, stability and function (48). The anti-synthetase antibodies target tRNA synthetases, cytoplasmic enzymes that generate aminoacyl tRNAs for protein translation, but may have other roles in the cell as well (36).

MSAs tend to occur with different frequencies in various patient populations and several MSAs are known to be genetically associated with HLA haplotypes. Anti-Mi-2 autoantibodies are associated with HLA DRB $1^{*} 0302$ and DRB $1{ }^{*} 0701 /$ DQA $1 * 0201$, differing in that DRB $1{ }^{*} 0302$ is often seen in African Americans and DRB1*0701/ DQA1*0201 is often seen in European Americans (57-61). HLA-DRB $1{ }^{*} 04$ and HLA-DQA $1{ }^{*} 03$ are risk factors for the development of anti-Mi-2 autoantibodies in Native Americans (61). While associated with development of anti-Mi-2 antibodies, the linked alleles DRB1*0701/ DQA1*0201 may be protective against the development of anti-Jo-1 antibodies (58). Anti-MDA-5 autoantibodies are associated with DRB1*0401, DRB1*1202, DRB1*1201, and DRB1*0901 in Chinese (62,63). Anti-TIF- $1 \gamma$ antibodies are associated with DQB1*02:02 in Caucasian adults and DQB1*02:01 in Caucasian children (21).

Beyond genetic associations, certain MSAs may be associated with environmental exposures. In particular, antiMi-2 and anti-TIF-1 $\gamma$ antibodies may be associated with UV exposure (64-68).

MSAs are associated with a variety of clinical phenotypes that potentially could impact clinical care decision making (Table 1). Two of these clinically important outcomes are the risk of internal malignancy and ILD. In a large study in 


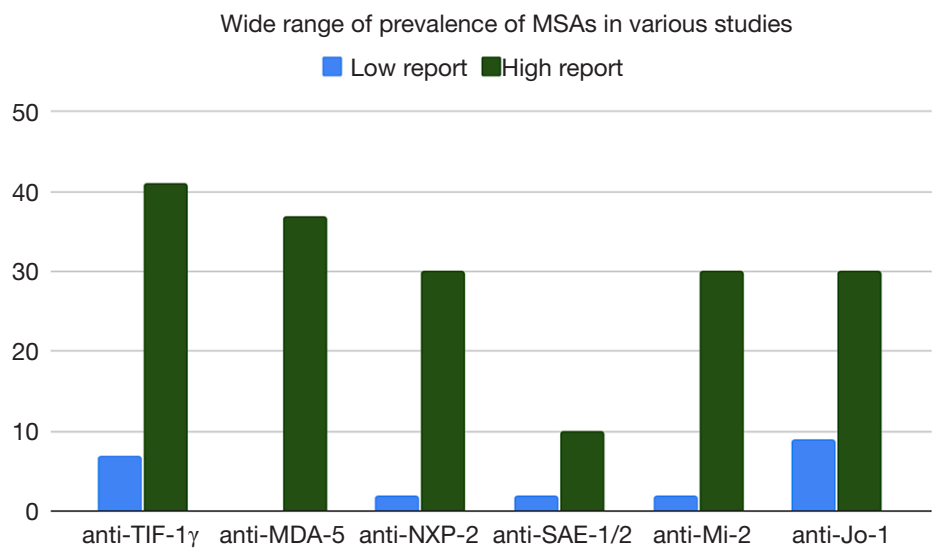

Figure 1 Wide range of prevalence of major MSAs in various studies. Anti-TIF-1 $\gamma$ : low report: 7\% (Japan, anti-TIF-1 $\gamma /$ anti-TIF-1 $\alpha$, IP) (16); high report: 41\% (USA, IP) (86). Anti-MDA-5: low report: 0\% (Hungary, IP) (87); high report: 37\% (China, ELISA) (88). Anti-NXP-2: low report: 2\% (Japan, IP) (42); high report: 30\% (Italy, IP) (89). Anti-SAE-1/2: low report: 2\% (Japan, IP) (90); high report: 10\% (UK, IP) (48). Anti-Mi-2: low report: 2\% (Japan, IP) (16); high report: 30\% (India, LIA) (91). Anti-Jo-1: low report: 9\% (Italy, LIA) (92); high report: 30\% (USA, African Americans, IP) (93). MSAs, myositis-specific autoantibodies; IP, immunoprecipitation; ELISA, enzyme-linked immunosorbent assay.

USA, $83 \%$ of DM patients who developed cancer had antiTIF- $1 \gamma$ or anti-NXP-2 antibodies, and numerous studies have associated anti-TIF-1 $\gamma$ antibodies with diagnosis of malignancy $(6,9)$. However, these data are limited by the fact that they are only relative risks and say nothing about the general risk for cancer in each antibody group compared to control patients. It is quite possible that, compared to a control population, the other DM-specific antibodies are also associated with an increased risk of internal malignancy. Similarly, anti-MDA-5 antibodies are associated with ILD, but both the prevalence as well as severity of the anti-MDA5 -associated ILD vary greatly between studies of patients from very different populations (16,51,69-79).

MSAs may be associated with differential response to treatments. As examples, anti-Mi-2 patients experience greater and more rapid benefit from rituximab, patients with anti-MDA-5 antibodies have lower chance of achieving cutaneous clinical remission even after aggressive systemic therapies, and patients with anti-SAE-1/2 antibodies are more likely to have hydroxychloroquine-related skin eruptions whereas anti-MDA-5 antibodies appear to be protective for this $(16,80-85)$.

\section{Uncertainty regarding prevalence of MSAs}

Because there is high variability in reports of MSA prevalence and strength of association with various DM- associated morbidities (Figure 1, Table 1), the utility of a test result to guide clinical decision-making is presently unclear.

Anti-TIF-1 $\gamma$, anti-NXP-2, and anti-SAE antibodies tend to be more prevalent in studies conducted in USA and Europe than in studies conducted in Asia. For example, anti-TIF- $1 \gamma$ antibody prevalence in DM ranges from $8-41 \%$ in USA and Europe compared to only $7-14 \%$ in Japan $(6,16,46,86,87,94-96)$. Similarly, anti-NXP-2 antibody prevalence in DM ranges from $3-30 \%$ in USA and Europe and only $2-4 \%$ in Japan $(6,42,43,87,89,97-99)$. Less pronounced is the anti-SAE antibody prevalence difference in DM which ranges from $5-10 \%$ in USA and Europe compared to $2-3 \%$ in Asia (48,87,90,100-104). In contrast, anti-MDA-5 autoantibodies are found in a much larger percentage of Asian DM patients, 11-37\%, compared to only $0-13 \%$ in patients from Europe and USA $(16,72,77,87,88,105)$. Anti-Mi-2 antibodies are found in similar percentages in DM patients around the world: in Asia ranging from 2-30\%, in Brazil around 8\%, and in Europe and USA ranging from 10-21\% (16,44,64,91-93,106-112). Meta-analysis of prevalence of anti-Mi-2 antibodies across studies found 9\% prevalence in DM patients with $95 \%$ confidence interval of $9-14 \%$ (113). Among ASAs, antiJo-1 is most common with prevalence in DM patients from Asia ranging from 10-14\% compared to 9-22\% in USA and Europe, though African American DM patients have a higher prevalence of around 30\% (44,91-93,109-111). 


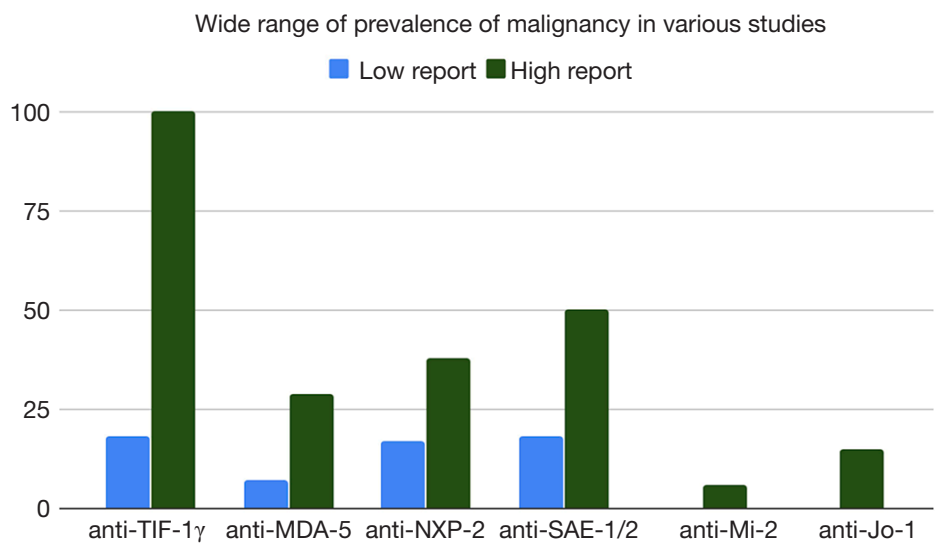

Figure 2 Wide range of prevalence of malignancy in various studies. Anti-TIF-1 $\gamma$ : low report: 18\% (USA, IP) (6); high report: 100\% (Japan, anti-TIF-1 $\gamma$ /anti-TIF-1 $\alpha$, IP) (70). Anti-MDA-5: low report: 7\% (China, ELISA) (77); high report: 29\% (ELISA and immunoblot) (78). Anti-NXP-2: low report: 17\% (Europe, IP) (18); high report: 38\% (Japan, IP) (42). Anti-SAE-1/2: low report: 18\% (UK, IP) (100); high report: 50\% (Japan, ELISA and IP) (115). Anti-Mi-2: low report: 0\% (Japan, IP) (116); high report: 6\% (USA, ELISA) (37). Anti-Jo-1: low report: 0\% (Hungary, immune serology otherwise unspecified) (117); high report: 15\% (Japan, IP) (114). IP, immunoprecipitation; ELISA, enzyme-linked immunosorbent assay.

Meta-analysis found $11 \%$ prevalence of anti-Jo-1 in DM patients with $95 \%$ confidence interval of $9-14 \%$ (113). Also in this meta-analysis, anti-PL-7 antibodies were detected in $2 \%$ of DM patients, anti-PL-12 in 3\%, anti-KS in $1 \%$, anti-OJ in $1 \%$, and anti-EJ in $1 \%$ (113). Restricting to DM-like patients with antisynthetase antibodies, a study in Japan found the prevalences to be anti-Jo-1 (36\%), antiEJ (23\%), anti-PL-7 (18\%), anti-PL-12 (11\%), anti-KS $(8 \%)$, and anti-OJ (5\%) (114).

\section{Antibodies and clinical associations with malignancy and ILD: uncertain risks}

Anti-TIF- $1 \gamma$ antibodies have a very strong association with cancer, but there is a large range in internal malignancy prevalence in the various reported studies (Figure 2) $(6,16,18,46,70,86,96,118-121)$. Though the prevalence of cancer in anti-TIF- $1 \gamma$ patients tends to be higher in Japan (38-68\%) versus the USA (18-46\%), the ranges vary between studies and are overlapping $(6,16,46,86,96)$. In patients with anti-NXP-2 antibodies, around $38 \%$ in Japan and around 24\% in the USA develop internal malignancy $(6,42)$. Anti-NXP-2 autoantibodies were found to have a 3.68 increased risk of cancer relative to the general population in a study of 56 anti-NXP-2 patients compared with 179 other DM patients (97). However, in a study of 20 anti-NXP-2 patients compared with 158 other DM patients, the increase in prevalence of internal malignancy was not statistically significant, and a recent large study out of Europe that included 1,483 IIM patients did not find an association between antiNXP-2 antibodies and cancer $(18,43)$. Anti-aminoacyltRNA synthetase (anti-ARS) patients have up to $12 \%$ malignancy with rates for anti-Jo-1 (15\%), anti-OJ (25\%), anti-PL-12 (16\%), and anti-KS (15\%) being somewhat higher, and rates for anti-EJ (3\%) and antiPL-7 (7\%) being somewhat lower (114). However, an earlier study of $103 \mathrm{DM}$ patients found $16 \%$ had anti-Jo-1 antibodies none of whom had associated malignancy (117). Anti-Mi-2 patients have generally been considered to be associated with relative lower rates of malignancy, for example $0 \%$ in Japan and $6 \%$ in USA $(37,81,116)$. However, this is not uniform, and recent studies have found significant association between anti-Mi-2 antibodies and malignancy $(18,122)$. A recent large study suggested an anti-Mi-2 cancer association with odds ratio 2.50 for developing cancer in anti-Mi-2 patients compared to odds ratio of 4.67 for antiTIF- $1 \gamma$ patients (18). Reports of malignancy in anti-MDA-5 patients are rare likely due to the major concern of ILD in these patients, however one study in China reports that 7\% of anti-MDA-5 patients had malignancy and another study in Spain reported 29\% (77,78).

The lack of agreement on predictive values of antibody tests for malignancy can create uncertainty on the part 


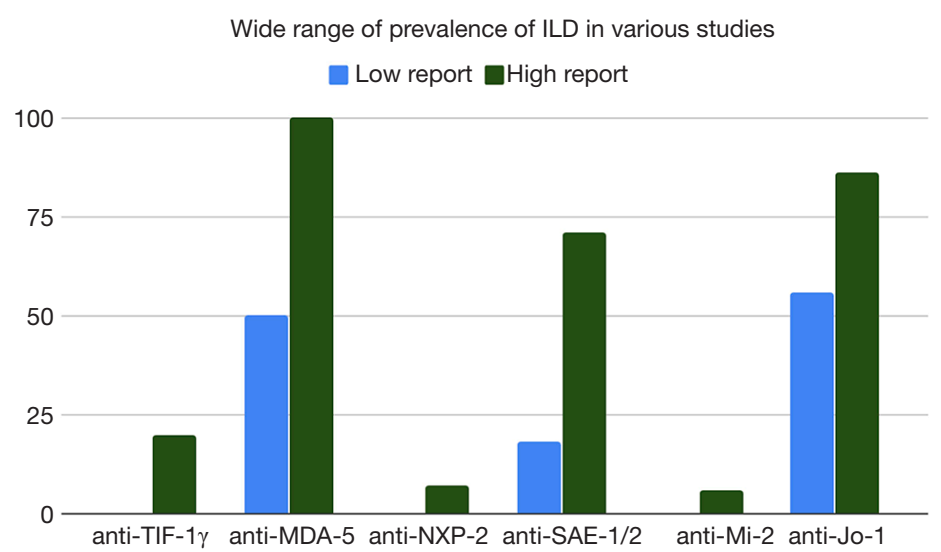

Figure 3 Wide range of prevalence of ILD in various studies. Anti-TIF-1 $\gamma$ : low report: 0\% (Spain, IP, method of evaluating ILD unspecified) (118); high report: 20\% (Japan, IP, chest radiography and high-resolution CT) (70). Anti-MDA-5: low report: 50\% (USA, ELISA, pulmonary fibrosis seen on chest radiography or high-resolution CT) (74); high report: 100\% (Japan, IP, chest radiography and high-resolution CT) (70). Anti-NXP-2: low report: 0\% (Japan, IP, standard clinical criteria) (42); high report: 7\% (USA, IP, percentage of FVC) (97). Anti-SAE-1/2: low report: 18\% (UK, IP, high resolution CT scan) (100); high report: 71\% (Japan, IP, method of evaluating ILD unspecified) (90). Anti-Mi-2: low report: 0\% (India, LIA, high-resolution CT) (91); high report: 6\% (Brazil, LIA, high-resolution CT) (127). Anti-Jo-1: low report: 56\% (Japan, IP, chest radiograph and high-resolution CT) (114); high report: 86\% (USA, ELISA, abnormalities on chest radiograph or high-resolution CT or biopsy) (128). ILD, interstitial lung disease; IP, immunoprecipitation; CT, computed tomography; LIA, line immunoblot assay.

of both physician and patient. For example, a patient in USA with a new diagnosis of DM and a positive test for anti-TIF- $1 \gamma$ antibodies may get the impression that this is a cancer-associated antibody, although, in USA for example, $75-80 \%$ of patients in this population will still be cancer-free (6). This may lead to unnecessarily aggressive cancer screening, cost, patient concern, and anxiety over ultimately benign lesions from comprehensive imaging procedures. In addition, internal malignancy can occur in all MSA subgroups, albeit at varying frequencies, and so, understandably, with the current data a physician may be tempted to screen all patients equivalently for cancer. Indeed, because of this uncertainty, malignancy and ILD screening are still currently recommended for all patients with DM regardless of autoantibody type $(7,123)$. Data from two large USA cohorts suggest that blind screening for malignancy consisting largely of computed tomography (CT) scans will indeed detect a significant number of cancers that would otherwise have been missed (124). Other data derived from insurance claims data in USA similarly suggest that age and sex-appropriate cancer screening likely does not detect a significant proportion of occult malignancies in young patients with DM (125). A greater understanding of the role of antibodies in the context of other clinical factors to stratify malignancy risk would help alleviate cost considerations as well as adverse effects of unnecessary screening procedures.

Variability also exists with regards to the risk of ILD, and especially rapidly-progressive ILD, in patients with anti-MDA-5 antibodies. In an early study of $82 \mathrm{DM}$ patients, $95 \%$ of anti-MDA-5 patients identified by immunoprecipitation (IP) had ILD (126). However, a study of adult patients using enzyme-linked immunosorbent assay (ELISA) at the University of Pittsburgh found that only $50 \%$ of anti-MDA-5 patients had ILD compared with $26 \%$ of DM patients who were not anti-MDA-5 positive (Figure 3) (74). Though in pooled studies for anti-MDA5 -positive patients, 5 -year survival was only $56 \%$, mainly due to ILD, this may be due to results from East Asia where anti-MDA-5-associated ILD is associated with a rapidly progressive course and high mortality (16,51,69-79). While patients with anti-MDA-5 antibodies may have ILD with rapidly progressive course in other populations, the incidence of this outcome appears to be lower $(72,74)$.

Anti-SAE-positive patients appear to have a high percentage of ILD (64-71\%) in Asia, but a much lower percentage (around 18\%) in Europe $(90,100,104)$. Other MSAs have very low levels of ILD: anti-Mi-2 (0\% in Asia and 
$6 \%$ in Brazil), anti-NXP-2 (0\% in Japan and 7\% in USA), and anti-TIF-1 $\gamma(0-20 \%$ in Japan and $0-5 \%$ in Europe and USA) $(42,46,70,86,91,96,97,99,116,118,126,127)$. Although many groups have a relatively lower risk of ILD, it is still possible that their risk of ILD is much higher than healthy comparators. To provide patients with early treatment, which is presumably associated with better outcomes, it is important to accurately identify groups that are susceptible. Overly aggressive treatment in a patient who is not at risk has its costs including sometimes fatal consequences (129).

\section{The current state of MSA testing in the clinic}

Depending on the geographic area of clinical practice, MSA assays are not always readily available to the practicing clinician. Even in situations in which they are available, many physicians do not have a clear idea which laboratory is the preferred vendor for accurate testing. For example, in USA, many laboratories have their own proprietary assay for testing that can vary widely. This means that the results of a given MSA assay need to be interpreted very differently depending on the laboratory, since assay platform is critical for interpreting results. In addition, many busy clinicians are unaware of these important nuances, and may interpret a false positive or negative result with misguided concern or comfort with regards to patient risk. Also, many of these assays have turnaround times of several weeks to even months which has obvious potentially adverse clinical implications as in the situation in which a patient is suffering from rapidly progressive lung disease whose etiology is unclear.

\section{The importance of population characteristics in interpreting autoantibody significance}

There is a critical need to consider population characteristics in order to interpret significance of any test or study. Population characteristics include not only geography, environmental exposures, ethnicity, gender, and age, but also the underlying disease of the patient. Autoantibody associations may depend on the underlying disease in which the study takes place. For example, anti-Ro52 antibodies are associated with Sjogren's disease in one population, with neonatal lupus and congenital heart block in another, with certain mucocutaneous features in lupus patients, with increased risk of ILD in systemic sclerosis, and with more severe muscle disease, and possibly ILD, in myositis
(130,131). For each MSA, varying numbers of patients may have only skin disease, only muscle disease (myositis), or varying states of overlap or DM-like disease-thus one might expect different associations depending on the clinical phenotype being studied. For example, originally, DM classification criteria required muscle involvement, and amyopathic DM was not included until recently (132-134). Recent criteria are still not very sensitive to detect amyopathic DM which may represent approximately 20\% of DM cases with similar morbidities and mortalities as myopathic DM including cancer rates (7,25,135-138). Thus, the classification of DM continues to be a moving target and remains a real challenge for standardizing phenotypes associated with specific autoantibodies.

In addition, antibody associations for the MSA appear, at least in some instances, to depend on underlying demographics of the patients. For example, rapidly progressive ILD in the anti-MDA-5 population appears to be more likely in Asian than non-Asian populations (16,51,69-79). Another notable population difference is seen in the association of anti-SAE antibodies and malignancy which is around $50 \%$ in Japan, but only $13-20 \%$ in USA and Europe $(87,100,101,115)$. In Japan, the standardized incidence ratio for cancer in anti-SAE patients was 13 relative to a matched normal population and may be enriched for cancers of the GI tract (139). The sensitivity and specificity of anti-TIF- $1 \gamma$ for cancer in adult patients with DM is approximately $70 \%$ and $89 \%$ respectively (140). In addition, younger adults and children with DM with anti-TIF- $1 \gamma$ antibodies do not appear to have a significantly increased risk of malignancy, pointing to the importance of age in assessing antibody phenotype $(6,47,141,142)$. Thus, antibody-associated risk for cancer, and its specific types, might be influenced by the demographics of the patient.

\section{The critical importance of autoantibody assay platform in interpreting autoantibody significance}

Though differences in MSA prevalence may be partially due to genetic and environmental factors, autoantibody prevalence also differs significantly between studies conducted in similar populations, raising questions about the consistency of various MSA detection methods $(65,143)$.

It is well known that there are many methodologies currently employed to detect autoantibodies. The gold standard assay is IP using native protein as the antigen, as it is clear that the immune system overwhelmingly 
Table 2 Autoantibody detection assays and their characteristics

\begin{tabular}{lll}
\hline Assay & Benefits & Limitations \\
\hline IP & $\begin{array}{l}\text { Gold standard-mimics native } \\
\text { antigen structure }\end{array}$ & Labor intensive, less reproducible, lack of precise quantitation \\
ELISA, bead-based assays & $\begin{array}{l}\text { Reproducible, quantitative, } \\
\text { affordable, scalable }\end{array}$ & Need validation against IP for each specificity \\
LIA and immunodot & $\begin{array}{l}\text { Reproducible, semi-quantitative, } \\
\text { scalable, widely available as } \\
\text { commercial kits }\end{array}$ & $\begin{array}{l}\text { Antigen is denatured (potential for false positive/negative), requires } \\
\text { validation against IP for each specificity. LIA poorly sensitive for } \\
\text { detecting anti-TIF1- } \gamma \text { antibodies }\end{array}$ \\
\hline
\end{tabular}

IP, immunoprecipitation; ELISA, enzyme-linked immunosorbent assay; LIA, line immunoblot assay.

sees antigen in its native conformation, but this is highly labor intensive and may be influenced by protein-protein interactions and post-translational modifications of the target antigen (Table 2) (144). It should be noted that this doesn't mean IP is always "correct", just that studies should always be comparing data from their platform with that from IP, and preferentially with some phenotypic characterization of the groups to delineate how different platforms might be detecting different subsets of patients. ELISA is more affordable with advantages that include standardization, large-scale reproducibility, and quantitative results, but does not necessarily always provide the same set of antigenic epitopes as do IP assays (36). Similarly, bead-based assays have been employed to detect certain MSAs (145). Finally, assays to detect non-native denatured forms of the antigens are in wide use, in the form of lineblot or dot-blot assays (146). In clinical laboratories, it is common to use a combination of these methodologiesa popular example would be screening with the use of indirect immunofluorescence followed by verification with automated monospecific immunoassays or multi-specific immunoassays, often commercial line/dot immunoassays $(5,27,147)$.

Early data using the MSAs suggested that assay platform is critical in interpreting results. For example, though multiple studies have shown that anti-Mi-2 antibodies are specific to DM, a large group of patients with polymyositis were detected by ELISA using fragments of the full-length $\mathrm{Mi}-2$ protein, raising doubt as to whether these patients were the same population that would be considered classic anti-Mi-2 patients $(37,81)$.

In light of this, several recent studies have cross-validated some of these platforms by testing the same sera using multiple assays (148-150). This discussion will be limited to studies that compared results to IP as the latter is considered an important reference. One early study compared commercial line immunoblot assay (LIA) with IP for 208 patients, finding $100 \%$ specificity and comparable sensitivity for anti-Jo-1 (92). Several recent studies compared the Euroline line immunoassay with IP $(145,151,152)$. Most of these studies find good test performance for anti-Jo-1 antibodies (145). These studies highlight a major issue that arises in these validation studies-that is, they include a large majority of seronegative patients, which can give falsely high concordance rates driven by the negative samples. Thus, one study found "good" agreement between line blot and IP for detecting antibodies against TIF- $1 \gamma$ and MDA-5, despite the fact that only 4 patients tested positive for each antibody (151). Later studies have confirmed that the Euroline blot misses a significant number of patients that are positive for anti-TIF- $1 \gamma$ antibodies by IP $(149,153)$. For example, our recent data revealed that the Euroline line blot was shown to miss $8 / 26$ anti-TIF- $1 \gamma$ positives by IP (149). Early studies also suggested that, the Euroline line blot assay, which detects anti-Mi-2 $\alpha$ and anti-Mi$2 \beta$ separately, is fraught with false positives. It has more recently been confirmed that, using the Euroline, anti-Mi$2 \alpha$ is sensitive and specific, but anti-Mi-2 $\beta$ suffers from lower sensitivity and much lower specificity $(154,155)$. It was suggested that more stringent cutoff values would improve the performance of the line assay, but this was not helpful for the performance for anti-TIF- $1 \gamma$, and obviously would not ameliorate instances where sensitivity is already a problem $(156,157)$. For example, for anti-NXP2 and antiSAE-1, there are significant numbers of "false" positives on the Euroline (e.g., not positive on IP), while the line blot appears to have an issue with lower sensitivity in detecting anti-NXP2 antibodies (much as the case for anti-TIF-1 $\gamma$ ) (149,151-153).

Other platforms have been less frequently validated 
against IP for the DM-specific MSA. In a study of 157 IIM patients from the United Kingdom, a fully automated particle-based multi-analyte technology (PMAT) test was compared with IP and demonstrated high agreement between the methods for all of the DM-specific antibodies, though this will need to be validated in other studies (153).

ELISA assays are being commonly employed for some specificities in detecting MSA in DM. Three ELISA assays have been developed in Japan for detecting antibodies against MDA-5, TIF- $1 \gamma$, and Mi-2 $\beta$ and were shown to be highly specific and sensitive in cohorts of Japanese patients $(158,159)$. Using the ELISA to detect anti-TIF$1 \gamma$ antibodies, a proportion of patients had low titers and it was suggested that these represent false positive patients that are actually anti-Mi-2-positive but have cross-reacting antibodies that can detect TIF- $1 \gamma$ (159). Our studies in USA patients also suggest that the anti-MDA-5 ELISAs are highly sensitive and specific, but that the ELISA detects another $25 \%$ positive for antibodies against Mi-2 and TIF$1 \gamma$, whose significance is unclear, but these do not appear to be due to cross-reactivity (149).

One question arises as to if the IP assay is always the "correct" gold standard. In a recent study, LIA, IP, and ELISA detected anti-TIF- $1 \gamma$ antibodies in increasingly larger nested sets of patients (149). The question then arises which is the "correct" assay to be considering. If one considers association with internal malignancy as a critical phenotype that "validates" anti-TIF- $1 \gamma$ positivity, this study found decreasing prevalence of malignancy using the LIA, IP, and ELISA assays, respectively (149). However, the "lowest" rate of malignancy found in the "ELISApositive only" group still was greater than that found in patients without anti-TIF- $1 \gamma$ antibodies, leaving open the question if this is still a unique subset of patients that is not equivalent to the anti-TIF- $1 \gamma$-negative group. Further studies in large numbers of patients with careful phenotypic characterization will be required to answer these questions.

As implied above, preferred assays for MSA detection may vary by antibody type. For example, ELISA assays for anti-MDA-5 may be superior to IP, given their comparable sensitivity and specificity, rapid turnaround, high-throughput, and availability for quantitation $(71,149)$. Line blot assays appear sufficient for detecting anti-Jo-1 antibodies, and, if one uses anti- Mi-2 $\alpha$ as the readout, also for Mi-2 antibodies (154). The data on using the line blot for detecting anti-SAE-1 antibodies are conflicting, with some studies suggesting that there are a significant number of false positives by line blot $(145,149)$. Current data suggest that line blot assay for anti-NXP-2 antibodies is neither adequately sensitive nor specific when compared to IP $(145,149)$.

While there is a need to standardize the more modern scalable immunoassays for DM autoantibodies to the classic IP assay, there might also be a need to standardize the classic IP assay as well. Some workers have used K562 cell extract as autoantigen source in their IP assays while other workers have used Hela cells $(16,42,87,118)$. It is conceivable that DM autoantigen configurations could vary between different cultured cell lines used as cell extracts in IP assays. It is also conceivable that Mycoplasma contamination of cultured cell line extracts could alter DM autoantigen configurations. Thus, it would seem reasonable that any cooperative effort to standardize modern DM autoantibody assays should also include efforts to standardize cell culture extracts in IP assays.

\section{Increasing the utility of the MSAs: define the patient population}

For the reasons mentioned previously, when reporting studies and results, the patient population needs to be welldefined. The recent ACR/EULAR classification criteria have gone a long way to help define myositis and its subgroups (25). However, it is still clear that these criteria do not capture up to a third of DM patients with skinpredominant disease (135). Further work is needed to define the population of DM that presents with mostly cutaneous manifestations, as there is currently lack of validation and diagnostic utility of the diverse cutaneous manifestations of DM (Table 1) $(43,72,76,86,130,136,160-162)$. A project is ongoing to validate skin criteria for DM classification, including morphology, distribution, symptoms, pathology, and contextual factors (135). This may assist to verify that patients have DM and not another related condition before being included in studies.

In many instances broad statements about autoantibody associations need to be nuanced with regards to the context of the particular population of included patients. More homogenous populations in terms of demographics need to be used in studies, and, although there is often power in large numbers, there may be great utility in resisting the urge to pool data from multiple diverse populations.

More detailed definition of outcomes is needed to highlight the nuances of autoantibody associations. For example, ovarian cancer seems more likely in anti-TIF$1 \gamma$ patients and GI cancers seem more likely in anti-SAE 
patients holding potential to direct screening procedures to correct populations $(139,163)$.

\section{Increasing the utility of the MSAs: optimize and standardize testing}

In addition to stratifying patient populations, more data are needed with respect to implications of antibody titer and isotype. Some data suggest that anti-MDA-5 and antiTIF- $1 \gamma$ titers tend to go down with decreased activity and remission and go up with potential flares (47,75,164-166). The IgG2 isotype of anti-TIF- $1 \gamma$ may be predictive of malignancy (167).

There is a need to continue to validate various assay platforms for each autoantibody against the "reference standard" of IP, and this needs to be done in multiple populations. IP has shortcomings as it is slow, not quantitative, difficult to reproduce, and not scalable, but other platforms must be validated before they can be adopted. Where differences exist between a given platform and IP, other data should be used to characterize specifically populations that are discordant in order to better understand what these tests might be detecting. In addition, many of the published validation studies do not have high numbers of positives for many of the DM-specific MSAs, and so apparently acceptable agreement between the assays is driven largely by all of the true negatives, with significant numbers of false positives and false negatives remaining $(145,149-151)$. In order to test and validate assays, large populations of patients likely positive for the antibody in question are needed in addition to negative controls (153). Carefully defined cutoffs for assigning positive antibody status are also needed for each assay $(155,168)$.

To be useful in helping understand differences between population, standardizing testing is a priority that will require assembling international groups of experts in order to look at all data to decide which platforms should be considered acceptable both clinically and for translational research $(31,149)$. There is currently an effort lead by the International Myositis Assessment and Clinical Studies (IMACS) group that has developed a Myositis Autoantibody Scientific Interest Group, established in 2018. One of the goals of this group is to define current practice and knowledge gaps with the ultimate goal of identifying valid testing platforms and harmonizing international testing practices (31). At present, most of the choices around selection of assay platform, at least in USA, is driven by economics and not data. Ultimately, these newer kinds of efforts should lead to endorsement of particular MSA assay platforms and best practices by national and international clinical societies that will drive changes in standard of practice and put the field in order. Despite concerns regarding reliability of results, commercial immunoassays are already being used globally to inform clinical decision making and there is no putting the genie back in the bottle (31). It is therefore critical to have reliable information about these assays and well-defined standards.

\section{Closing}

It is a challenging fact of life that DM and related disorders have overlapping and variably penetrant phenotypes. Like any test, the diagnostic sensitivity and specificity of assays for various MSAs will not be perfect. However, this does not mean that we should not continue to optimize methods of using the tests as effectively as possible. Currently tests for MSAs are helpful at minimum for a clinician to assess relative risk or contribute to diagnosis and perhaps counsel the appropriate patient about what to expect (e.g., NXP-2 patient to watch for calcinosis) $(169,170)$. With international standardization and larger studies, it is likely that more antibody tests will make their way into formal schemata for diagnosis and actionable risk assessment in DM.

\section{Acknowledgments}

Funding: None.

\section{Footnote}

Provenance and Peer Review: This article was commissioned by the editorial office, Annals of Translational Medicine for the series "Rheumatologic Skin Disease". The article has undergone external peer review.

Peer Review File: Available at http://dx.doi.org/10.21037/ atm-20-5175

Conflicts of Interest: All authors have completed the ICMJE uniform disclosure form (available at http://dx.doi. org/10.21037/atm-20-5175). The series "Rheumatologic Skin Disease" was commissioned by the editorial office without any funding or sponsorship. DFF served as the unpaid Guest Editor of the series. The authors have no 
other conflicts of interest to declare.

Ethical Statement: The authors are accountable for all aspects of the work in ensuring that questions related to the accuracy or integrity of any part of the work are appropriately investigated and resolved.

Open Access Statement: This is an Open Access article distributed in accordance with the Creative Commons Attribution-NonCommercial-NoDerivs 4.0 International License (CC BY-NC-ND 4.0), which permits the noncommercial replication and distribution of the article with the strict proviso that no changes or edits are made and the original work is properly cited (including links to both the formal publication through the relevant DOI and the license). See: https://creativecommons.org/licenses/by-nc-nd/4.0/.

\section{References}

1. Mariampillai K, Granger B, Amelin D, et al. Development of a new classification system for idiopathic inflammatory myopathies based on clinical manifestations and myositisspecific autoantibodies. JAMA Neurol 2018;75:1528-37.

2. Senécal JL, Raynauld JP, Troyanov Y. A new classification of autoimmune myositis. Arthritis Rheumatol 2017;69:878-84.

3. McHugh NJ, Tansley SL. Autoantibodies in myositis. Nat Rev Rheumatol 2018;14:290-302.

4. Lundberg IE, de Visser M, Werth VP. Classification of myositis. Nat Rev Rheumatol 2018;14:269-78.

5. Damoiseaux J, Vulsteke JB, Tseng CW, et al. Autoantibodies in idiopathic inflammatory myopathies: clinical associations and laboratory evaluation by monoand multispecific immunoassays. Autoimmun Rev 2019; 18:293-305.

6. Fiorentino DF, Chung LS, Christopher-Stine L, et al. Most patients with cancer-associated dermatomyositis have antibodies to nuclear matrix protein NXP-2 or transcription intermediary factor $1 \gamma$. Arthritis Rheum 2013;65:2954-62.

7. Thomas C, Vleugels RA, Kwiatkowski DJ, et al. Facing uncertainty. N Engl J Med 2019;381:2253-9.

8. Maier L, Betteridge Z, Udvardi A, et al. Paraneoplastic dermatomyositis: relevance of myositis-specific autoantibodies in a small cohort. J Eur Acad Dermatol Venereol 2020;34:e50-1.

9. Best M, Molinari N, Chasset F, et al. Use of antitranscriptional intermediary factor- $1 \gamma$ autoantibody in identifying adult dermatomyositis patients with cancer: a systematic review and meta-analysis. Acta Derm Venereol 2019;99:256-62.

10. Cobos GA, Femia A, Vleugels RA. Dermatomyositis: an update on diagnosis and treatment. Am J Clin Dermatol 2020;21:339-53.

11. Gono T, Kuwana M. Dermatomyositis-associated autoantibodies: TIF1- $\gamma$, NXP2, and MDA5. In: Aggarwal $\mathrm{R}$, Oddis C. editors. Managing myositis: a practical guide. Cham: Springer, 2020:193-8.

12. Mammen AL, Allenbach Y, Stenzel W, et al. 239th ENMC International Workshop: classification of dermatomyositis, Amsterdam, the Netherlands, 14-16 December 2018. Neuromuscul Disord 2020;30:70-92.

13. DeWane ME, Waldman R, Lu J. Dermatomyositis: clinical features and pathogenesis. J Am Acad Dermatol 2020;82:267-81.

14. Wolstencroft PW, Fiorentino DF. Dermatomyositis clinical and pathological phenotypes associated with myositis-specific autoantibodies. Curr Rheumatol Rep 2018;20:28.

15. Marvi U, Chung L, Fiorentino DF. Clinical presentation and evaluation of dermatomyositis. Indian J Dermatol. 2012;57:375-81.

16. Hamaguchi Y, Kuwana M, Hoshino K, et al. Clinical correlations with dermatomyositis-specific autoantibodies in adult Japanese patients with dermatomyositis: a multicenter cross-sectional study. Arch Dermatol 2011;147:391-8.

17. Mammen AL. Autoimmune myopathies: autoantibodies, phenotypes and pathogenesis. Nat Rev Neurol 2011;7:343-54.

18. Betteridge Z, Tansley S, Shaddick G, et al. Frequency, mutual exclusivity and clinical associations of myositis autoantibodies in a combined European cohort of idiopathic inflammatory myopathy patients. J Autoimmun 2019;101:48-55.

19. Okiyama N, Yamaguchi Y, Kodera M, et al. Distinct histopathologic patterns of finger eruptions in dermatomyositis based on myositis-specific autoantibody profiles. JAMA Dermatol 2019;155:1080-2.

20. Pinal-Fernandez I, Casciola-Rosen LA, ChristopherStine L, et al. The prevalence of individual histopathologic features varies according to autoantibody status in muscle biopsies from patients with dermatomyositis. J Rheumatol 2015;42:1448-54.

21. Rothwell S, Chinoy H, Lamb JA, et al. Focused HLA analysis in Caucasians with myositis identifies significant associations with autoantibody subgroups. Ann Rheum Dis 
2019;78:996-1002.

22. Ye L, Zuo Y, Yang H, et al. Specific autoantibodies and clinical phenotypes correlate with the aberrant expression of immune-related MicroRNAs in Dermatomyositis. J Immunol Res 2019;2019:2927061.

23. Betteridge Z, McHugh N. Myositis-specific autoantibodies: an important tool to support diagnosis of myositis. J Intern Med 2016;280:8-23.

24. Fujimoto $M$, Watanabe R, Ishitsuka $Y$, et al. Recent advances in dermatomyositis-specific autoantibodies. Curr Opin Rheumatol 2016;28:636-644.

25. Lundberg IE, Tjarnlund A, Bottai M, et al. 2017 European League Against Rheumatism/American College of Rheumatology classification criteria for adult and juvenile idiopathic inflammatory myopathies and their major subgroups. Ann Rheum Dis 2017;76:1955-64.

26. Malaviya AN. EULAR/ACR classification criteria for adult and juvenile idiopathic inflammatory myopathies and their major subgroups: little emphasis on autoantibodies, why? Ann Rheum Dis 2018;77:e77.

27. Vulsteke JB, De Langhe E, Claeys KG, et al. Detection of myositis-specific antibodies. Ann Rheum Dis 2019;78:e7.

28. Cabezas-Rodríguez I, Morante-Bolado I, Brandy-García A, et al. Anti-MDA5 dermatomyositis mimicking psoriatic arthritis. Reumatol Clin 2018;14:224-6.

29. Marie I. Morbidity and mortality in adult polymyositis and dermatomyositis. Curr Rheumatol Rep 2012;14:275-85.

30. Kiely PDW, Chua F. Interstitial lung disease in inflammatory myopathies: clinical phenotypes and prognosis. Curr Rheumatol Rep 2013;15:359.

31. Tansley SL, Snowball J, Pauling JD, et al. The promise, perceptions, and pitfalls of immunoassays for autoantibody testing in myositis. Arthritis Res Ther 2020;22:117.

32. Eifler K, Vertegaal ACO. SUMOylation-mediated regulation of cell cycle progression and cancer. Trends Biochem Sci 2015;40:779-93.

33. Mahler M, Miller FW, Fritzler MJ. Idiopathic inflammatory myopathies and the anti-synthetase syndrome: a comprehensive review. Autoimmun Rev 2014;13:367-71.

34. Yoo IS, Kim J. The role of autoantibodies in idiopathic inflammatory myopathies. Rheum Dis 2019;26:165-78.

35. Nishikai M, Reichlin M. Heterogeneity of precipitating antibodies in polymyositis and dermatomyositis: characterization of the Jo-1 antibody system. Arthritis Rheum 1980;23:881-8.

36. Palterer B, Vitiello G, Carraresi A, et al. Bench to bedside review of myositis autoantibodies. Clin Mol Allergy
2018;16:5.

37. Targoff IN, Reichlin M. The association between Mi-2 antibodies and dermatomyositis. Arthritis Rheum 1985;28:796-803.

38. Reichlin M, Mattioli M. Description of a serological reaction characteristic of polymyositis. Clin Immunol Immunopathol 1976;5:12-20.

39. Oddis CV, Fertig N, Goel A, et al. Clinical and serological characterization of the anti-MJ antibody in childhood myositis. Arthritis Rheum 1997;40:652.

40. Targoff IN, Trieu EP, Levy-Neto M, et al. Sera with autoantibodies to the MJ antigen react with NXP2. Arthritis Rheum 2007;56:S787.

41. Gunawardena H, Betteridge ZE, McHugh NJ. Newly identified autoantibodies: relationship to idiopathic inflammatory myopathy subsets and pathogenesis. Curr Opin Rheumatol 2008;20:675-80.

42. Ichimura Y, Matsushita T, Hamaguchi Y, et al. AntiNXP2 autoantibodies in adult patients with idiopathic inflammatory myopathies: possible association with malignancy. Ann Rheum Dis 2012;71:710-3.

43. Rogers A, Chung L, Li S, et al. The cutaneous and systemic findings associated with nuclear matrix protein-2 antibodies in adult dermatomyositis patients. Arthritis Care Res (Hoboken) 2017;69:1909-14.

44. Sato S, Hirakata M, Kuwana M, et al. Autoantibodies to a 140-kd Polypeptide, CADM-140, in Japanese patients with clinically amyopathic dermatomyositis. Arthritis Rheum 2005;52:1571-6.

45. Ueda-Hayakawa I, Hamaguchi Y, Okiyama N, et al. Autoantibody to transcriptional intermediary factor- $1 \beta$ as a myositis-specific antibody: clinical correlation with clinically amyopathic dermatomyositis or dermatomyositis with mild myopathy. Br J Dermatol 2019;180:881-7.

46. Kaji K, Fujimoto M, Hasegawa M, et al. Identification of a novel autoantibody reactive with 155 and $140 \mathrm{kDa}$ nuclear proteins in patients with dermatomyositis: an association with malignancy. Rheumatology (Oxford). 2007;46:25-8.

47. Fujimoto M, Hamaguchi Y, Kaji K, et al. Myositisspecific anti-155/140 autoantibodies target transcription intermediary factor 1 family proteins. Arthritis Rheum 2012;64:513-22.

48. Betteridge Z, Gunawardena H, North J, et al. Identification of a novel autoantibody directed against small ubiquitin-like modifier activating enzyme in dermatomyositis. Arthritis Rheum 2007;56:3132-7.

49. Mammen AL, Casciola-Rosen LA, Hall JC, et al. Expression of the dermatomyositis autoantigen $\mathrm{Mi}-2$ in 
regenerating muscle. Arthritis Rheum 2009;60:3784-93.

50. Zhang Y, LeRoy G, Seelig HP, et al. The dermatomyositisspecific autoantigen $\mathrm{Mi} 2$ is a component of a complex containing histone deacetylase and nucleosome remodeling activities. Cell 1998;95:279-89.

51. Nakashima R, Imura Y, Kobayashi S, et al. The RIG-Ilike receptor IFIH1/MDA5 is a dermatomyositis-specific autoantigen identified by the anti-CADM-140 antibody. Rheumatology (Oxford) 2010;49:433-40.

52. Takahashi K, Yoshida N, Murakami N, et al. Dynamic regulation of p53 subnuclear localization and senescence by MORC3. Mol Biol Cell 2007;18:1701-9.

53. Muro Y, Ishikawa A, Sugiura K, et al. Clinical features of anti-TIF1- $\alpha$ antibody-positive dermatomyositis patients are closely associated with coexistent dermatomyositisspecific autoantibodies and anti-TIF1- $\gamma$ or anti-Mi-2 autoantibodies. Rheumatology (Oxford) 2012;51:1508-13.

54. Satoh M, Chan JY, Ross SJ, et al. Autoantibodies to transcription intermediary factor (TIF) $1 \beta$ associated with dermatomyositis. Arthritis Res Ther 2012;14:R79.

55. Agricola E, Randall RA, Gaarenstroom T, et al. Recruitment of TIF1 $\gamma$ to chromatin via its PHD finger-bromodomain activates its ubiquitin ligase and transcriptional repressor activities. Mol Cell 2011;43:85-96.

56. Kulkarni A, Oza J, Yao M, et al. Tripartite motif-containing 33 (TRIM33) protein functions in the poly(ADP-ribose) polymerase (PARP)-dependent DNA damage response through interaction with amplified in liver cancer 1 (ALC1) protein. J Biol Chem 2013;288:32357-69.

57. Ghirardello A, Doria A. New insights in myositis-specific autoantibodies. Curr Opin Rheumatol 2018;30:614-22.

58. O'Hanlon TP, Carrick DM, Targoff IN, et al. Immunogenetic risk and protective factors for the idiopathic inflammatory myopathies: distinct HLA-A, -B, - Cw, -DRB1, and -DQA1 allelic profiles distinguish European American patients with different myositis autoantibodies. Medicine (Baltimore) 2006;85:111-27.

59. O'Hanlon TP, Rider LG, Mamyrova G, et al. HLA polymorphisms in African Americans with idiopathic inflammatory myopathy: allelic profiles distinguish patients with different clinical phenotypes and myositis autoantibodies. Arthritis Rheum 2006;54:3670-81.

60. Mierau R, Dick T, Bartz-Bazzanella P, et al. Strong association of dermatomyositis-specific $\mathrm{Mi}-2$ autoantibodies with a tryptophan at position 9 of the HLA-DR beta chain. Arthritis Rheum 1996;39:868-76.

61. Shamim EA, Rider LG, Pandey JP, et al. Differences in idiopathic inflammatory myopathy phenotypes and genotypes between Mesoamerican Mestizos and North American Caucasians: ethnogeographic influences in the genetics and clinical expression of myositis. Arthritis Rheum 2002;46:1885-93.

62. Chen Z, Wang Y, Kuwana M, et al. HLA-DRB1 alleles as genetic risk factors for the development of anti-MDA5 antibodies in patients with dermatomyositis. J Rheumatol 2017;44:1389-93.

63. Lin JM, Zhang YB, Peng QL, et al. Genetic association of HLA-DRB1 multiple polymorphisms with dermatomyositis in Chinese population. HLA 2017;90:354-9.

64. Cruellas MG, Viana VST, Levy-Neto M, et al. Myositisspecific and myositis-associated autoantibody profiles and their clinical associations in a large series of patients with polymyositis and dermatomyositis. Clinics (Sao Paulo) 2013;68:909-14.

65. Petri MH, Satoh M, Martin-Marquez BT, et al. Implications in the difference of anti-Mi-2 and -p155/140 autoantibody prevalence in two dermatomyositis cohorts from Mexico City and Guadalajara. Arthritis Res Ther 2013;15:R48.

66. Love LA, Weinberg CR, McConnaughey DR, et al. Ultraviolet radiation intensity predicts the relative distribution of dermatomyositis and antiMi-2 autoantibodies in women. Arthritis Rheum 2009;60:2499-504.

67. Okada S, Weatherhead E, Targoff IN, et al. Global surface ultraviolet radiation intensity may modulate the clinical and immunologic expression of autoimmune muscle disease. Arthritis Rheum 2003;48:2285-93.

68. Shah M, Targoff IN, Rice MM, et al. Brief report: ultraviolet radiation exposure is associated with clinical and autoantibody phenotypes in juvenile myositis. Arthritis Rheum 2013;65:1934-41.

69. Chaisson NF, Paik J, Orbai AM, et al. A novel dermatopulmonary syndrome associated with MDA-5 antibodies: report of 2 cases and review of the literature. Medicine (Baltimore) 2012;91:220-8.

70. Fujikawa K, Kawakami A, Kaji K, et al. Association of distinct clinical subsets with myositis-specific autoantibodies towards anti-155/140-kDa polypeptides, anti-140-kDa polypeptides, and anti-aminoacyl tRNA synthetases in Japanese patients with dermatomyositis: a single-centre, cross-sectional study. Scand J Rheumatol 2009;38:263-7.

71. Sato S, Hoshino K, Satoh T, et al. RNA helicase encoded by melanoma differentiation-associated gene 5 is a 
major autoantigen in patients with clinically amyopathic dermatomyositis: association with rapidly progressive interstitial lung disease. Arthritis Rheum 2009;60:2193.

72. Fiorentino D, Chung L, Zwerner J, et al. The mucocutaneous and systemic phenotype of dermatomyositis patients with antibodies to MDA5 (CADM-140): a retrospective study. J Am Acad Dermatol 2011;65:25-34.

73. Kobayashi N, Takezaki S, Kobayashi I, et al. Clinical and laboratory features of fatal rapidly progressive interstitial lung disease associated with juvenile dermatomyositis. Rheumatology (Oxford) 2015;54:784-91.

74. Moghadam-Kia S, Oddis CV, Sata S, et al. Anti-melanoma differentiation-associated gene 5 is associated with rapidly progressive lung disease and poor survival in US patients with amyopathic and myopathic dermatomyositis. Arthritis Care Res (Hoboken) 2016;68:689-94.

75. Matsushita T, Mizumaki K, Kano M, et al. Antimelanoma differentiation-associated protein 5 antibody level is a novel tool for monitoring disease activity in rapidly progressive interstitial lung disease with dermatomyositis. Br J Dermatol 2017;176:395-402.

76. Best M, Jachiet M, Molinari N, et al. Distinctive cutaneous and systemic features associated with specific antimyositis antibodies in adults with dermatomyositis: a prospective multicentric study of 117 patients. J Eur Acad Dermatol Venereol 2018;32:1164-72.

77. Cao H, Pan M, Kang Y, et al. Clinical manifestations of dermatomyositis and clinically amyopathic dermatomyositis patients with positive expression of antimelanoma differentiation-associated gene 5 antibody. Arthritis Care Res (Hoboken) 2012;64:1602-10.

78. Labrador-Horrillo M, Martinez MA, Selva-O'Callaghan A, et al. Anti-MDA5 antibodies in a large Mediterranean population of adults with dermatomyositis. J Immunol Res 2014;2014:290797.

79. Li L, Wang Q, Wen X, et al. Assessment of anti-MDA5 antibody as a diagnostic biomarker in patients with dermatomyositis-associated interstitial lung disease or rapidly progressive interstitial lung disease. Oncotarget 2017;8:76129-40.

80. Love LA, Leff RL, Fraser DD, et al. A new approach to the classification of idiopathic inflammatory myopathy: myositis-specific autoantibodies define useful homogeneous patient groups. Medicine (Baltimore) 1991;70:360-74.

81. Hengstman GJ, Vree Egberts WT, Seelig HP, et al. Clinical characteristics of patients with myositis and autoantibodies to different fragments of the Mi-2 beta antigen. Ann Rheum Dis 2006;65:242-5.

82. Reed AM, Crowson CS, Hein M, et al. Biologic predictors of clinical improvement in rituximab-treated refractory myositis. BMC Musculoskelet Disord 2015;16:257.

83. Aggarwal R, Bandos A, Reed AM, et al. Predictors of clinical improvement in rituximab-treated refractory adult and juvenile dermatomyositis and adult polymyositis. Arthritis Rheumatol 2014;66:740-9.

84. Wolstencroft PW, Chung L, Li S, et al. Factors associated with clinical remission of skin disease in dermatomyositis. JAMA Dermatol 2018;154:44-51.

85. Wolstencroft PW, Casciola-Rosen L, Fiorentino DF. Association between autoantibody phenotype and cutaneous adverse reactions to hydroxychloroquine in dermatomyositis. JAMA Dermatol 2018;154:1199-203.

86. Fiorentino DF, Kuo K, Chung L, et al. Distinctive cutaneous and systemic features associated with antitranscriptional intermediary factor- $1 \gamma$ antibodies in adults with dermatomyositis. J Am Acad Dermatol 2015;72:449-55.

87. Bodoki L, Nagy-Vincze M, Griger Z, et al. Four dermatomyositis-specific autoantibodies-anti- TIF $1 \gamma$, antiNXP2, anti-SAE and anti-MDA5-in adult and juvenile patients with idiopathic inflammatory myopathies in a Hungarian cohort. Autoimmun Rev 2014;13:1211-9.

88. Chen Z, Hu W, Wang Y, et al. Distinct profiles of myositis-specific autoantibodies in Chinese and Japanese patients with polymyositis/dermatomyositis. Clin Rheumatol 2015;34:1627-31.

89. Ceribelli A, Fredi M, Taraborelli M, et al. Anti-MJ/NXP-2 autoantibody specificity in a cohort of adult Italian patients with polymyositis/dermatomyositis. Arthritis Res Ther 2012;14:R97.

90. Fujimoto M, Matsushita T, Hamaguchi Y, et al. Autoantibodies to small ubiquitin-like modifier activating enzymes in Japanese patients with dermatomyositis: comparison with a UK Caucasian cohort. Ann Rheum Dis 2013;72:151-3.

91. Srivastava P, Dwivedi S, Misra R. Myositis-specific and myositis-associated autoantibodies in Indian patients with inflammatory myositis. Rheumatol Int 2016;36:935-43.

92. Ghirardello A, Rampudda M, Ekholm L, et al. Diagnostic performance and validation of autoantibody testing in myositis by a commercial line blot assay. Rheumatology (Oxford) 2010;49:2370-4.

93. O'Hanlon TP, Rider LG, Schiffenbauer A, et al. Immunoglobulin gene polymorphisms are susceptibility 
factors in clinical and autoantibody subgroups of the idiopathic inflammatory myopathies. Arthritis Rheum 2008;58:3239-46.

94. Rider LG, Shah M, Mamyrova G, et al. The myositis autoantibody phenotypes of the juvenile idiopathic inflammatory myopathies. Medicine (Baltimore) 2013;92:223-43.

95. Deakin CT, Yasin SA, Simou S, et al. Muscle biopsy findings in combination with myositis-specific autoantibodies aid prediction of outcomes in juvenile dermatomyositis. Arthritis Rheumatol 2016;68:2806-16.

96. Targoff IN, Mamyrova G, Trieu EP, et al. A novel autoantibody to a $155-\mathrm{kd}$ protein is associated with dermatomyositis. Arthritis Rheum 2006;54:3682-9.

97. Albayda J, Pinal-Fernandez I, Huang W, et al. Antinuclear Matrix Protein 2 autoantibodies and edema, muscle disease, and malignancy risk in dermatomyositis patients. Arthritis Care Res (Hoboken) 2017;69:1771-6.

98. Gunawardena H, Wedderburn LR, Chinoy H, et al. Autoantibodies to a $140-\mathrm{kd}$ protein in juvenile dermatomyositis are associated with calcinosis. Arthritis Rheum 2009;60:1807-14.

99. Ishikawa A, Muro Y, Sugiura K, et al. Development of an ELISA for detection of autoantibodies to nuclear matrix protein 2. Rheumatology (Oxford) 2012;51:1181-7.

100. Betteridge ZE, Gunawardena H, Chinoy H, et al. Clinical and human leucocyte antigen class II haplotype associations of autoantibodies to small ubiquitin-like modifier enzyme, a dermatomyositis-specific autoantigen target, in UK Caucasian adult-onset myositis. Ann Rheum Dis 2009;68:1621-5.

101. Tarricone E, Ghirardello A, Rampudda M, et al. AntiSAE antibodies in autoimmune myositis: identification by unlabelled protein immunoprecipitation in an Italian patient cohort. J Immunol Methods 2012;384:128-34.

102. Muro Y, Sugiura K, Akiyama M. Low prevalence of anti-small ubiquitin-like modifier activating enzyme antibodies in dermatomyositis patients. Autoimmunity 2013;46:279-84.

103. Inoue S, Okiyama N, Shobo M, et al. Diffuse erythema with 'angel wings' sign in Japanese patients with anti-small ubiquitin-like modifier activating enzyme antibody-associated dermatomyositis. Br J Dermatol 2018;179:1414-5.

104. Ge Y, Lu X, Shu X, et al. Clinical characteristics of antiSAE antibodies in Chinese patients with dermatomyositis in comparison with different patient cohorts. Sci Rep 2017;7:188.
105. Hall JC, Casciola-Rosen L, Samedy LA, et al. Antimelanoma differentiation-associated protein 5 -associated dermatomyositis: expanding the clinical spectrum. Arthritis Care Res (Hoboken) 2013;65:1307-15.

106. Matsushita T, Hasegawa M, Fujimoto M, et al. Clinical evaluation of anti-aminoacyl tRNA synthetase antibodies in Japanese patients with dermatomyositis. J Rheumatol 2007;34:1012-8.

107.Kang EH, Nakashima R, Mimori T, et al. Myositis autoantibodies in Korean patients with inflammatory myositis: anti-140-kDa polypeptide antibody is primarily associated with rapidly progressive interstitial lung disease independent of clinically amyopathic dermatomyositis. BMC Musculoskelet Disord 2010;11:223.

108. Ikeda N, Takahashi K, Yamaguchi Y, et al. Analysis of dermatomyositis-specific autoantibodies and clinical characteristics in Japanese patients. J Dermatol 2011;38:973-9.

109. Selva-O'Callaghan A, Labrador-Horrillo M, SolansLaque R, et al. Myositis-specific and myositis-associated antibodies in a series of eighty-eight Mediterranean patients with idiopathic inflammatory myopathy. Arthritis Rheum 2006;55:791-8.

110. Chinoy H, Salway F, Fertig N, et al. In adult onset myositis, the presence of interstitial lung disease and myositis specific/associated antibodies are governed by HLA class II haplotype, rather than by myositis subtype. Arthritis Res Ther 2006;8:R13.

111.Hausmanowa-Petrusewicz I, Kowalska-Oledzka E, Miller FW, et al. Clinical, serologic, and immunogenetic features in Polish patients with idiopathic inflammatory myopathies. Arthritis Rheum 1997;40:1257-66.

112. Brouwer R, Hengstman GJ, Vree Egberts W, et al. Autoantibody profiles in the sera of European patients with myositis. Ann Rheum Dis 2001;60:116-23.

113.Lega JC, Fabien N, Reynaud Q, et al. The clinical phenotype associated with myositis-specific and associated autoantibodies: a meta-analysis revisiting the so-called antisynthetase syndrome. Autoimmun Rev 2014;13:883-91.

114. Hamaguchi Y, Fujimoto M, Matsushita T, et al. Common and distinct clinical features in adult patients with antiaminoacyl-tRNA synthetase antibodies: heterogeneity within the syndrome. PLoS One 2013;8:e60442.

115.Muro Y, Sugiura K, Nara M, et al. High incidence of cancer in anti-small ubiquitin-like modifier activating enzyme antibody-positive dermatomyositis. Rheumatology (Oxford) 2015;54:1745-7.

116. Komura K, Fujimoto M, Matsushita T, et al. Prevalence 
and clinical characteristics of anti-Mi-2 antibodies in Japanese patients with dermatomyositis. J Dermatol Sci 2005;40:215-7.

117.András C, Ponyi A, Constantin T, et al. Dermatomyositis and polymyositis associated with malignancy: a 21-year retrospective study. J Rheumatol 2008;35:438-44.

118. Trallero-Araguás E, Labrador-Horrillo M, SelvaO'Callaghan A, et al. Cancer-associated myositis and anti-p155 autoantibody in a series of 85 patients with idiopathic inflammatory myopathy. Medicine (Baltimore) 2010;89:47-52.

119. Hida A, Yamashita T, Hosono Y, et al. AntiTIF1- $\gamma$ antibody and cancer-associated myositis: A clinicohistopathologic study. Neurology 2016;87:299-308.

120.Li S, Ge Y, Yang H, et al. The spectrum and clinical significance of myositis-specific autoantibodies in Chinese patients with idiopathic inflammatory myopathies. Clin Rheumatol 2019;38:2171-9.

121. De Vooght J, Vulsteke JB, De Haes P, et al. Anti-TIF1- $\gamma$ autoantibodies: warning lights of a tumour autoantigen. Rheumatology (Oxford) 2020;59:469-77.

122. Monseau G, Landon-Cardinal O, Stenzel W, et al. Systematic retrospective study on 64 patients anti-Mi2 dermatomyositis: a classic skin rash with a necrotizing myositis and high risk of malignancy. J Am Acad Dermatol 2020;83:1759-63.

123. Selva-O'Callaghan A, Martinez-Gómez X, TralleroAraguás E, et al. The diagnostic work-up of cancerassociated myositis. Curr Opin Rheumatol 2018;30:630-6.

124. Leatham H, Schadt C, Chisolm S, et al. Evidence supports blind screening for internal malignancy in dermatomyositis: data from 2 large US dermatology cohorts. Medicine (Baltimore) 2018;97:e9639.

125. Kundrick A, Kitts S, Maczuga S, et al. Age- and sexappropriate cancer screening risks missing most occult malignancies in young patients with dermatomyositis. Br J Dermatol 2020;182:1283-5.

126. Hoshino K, Muro Y, Sugiura K, et al. Anti-MDA5 and anti-TIF-1 $\gamma$ antibodies have clinical significance for patients with dermatomyositis. Rheumatology (Oxford) 2010;49:1726-33.

127. Dos Passos Carvalho MIC, Shinjo SK. Frequency and clinical relevance of anti-Mi-2 autoantibody in adult Brazilian patients with dermatomyositis. Adv Rheumatol 2019;59:27.

128.Johnson C, Connors GR, Oaks J, et al. Clinical and pathologic differences in interstitial lung disease based on antisynthetase antibody type. Respir Med 2014;108:1542-8.
129. Sontheimer RD. MDA5 autoantibody-another indicator of clinical diversity in dermatomyositis. Ann Transl Med 2017;5:160.

130. Lee S, Findeisen J, McLean C, et al. Recalcitrant ulcers associated with anti-small ubiquitin-like modifier activating enzyme-positive dermatomyositis treated with surgery followed by intravenous immunoglobulin. Australas J Dermatol 2018;59:e76-8.

131.Pinal-Fernandez I, Mecoli CA, Casal-Dominguez M, et al. More prominent muscle involvement in patients with dermatomyositis with anti-Mi2 autoantibodies. Neurology 2019;93:e1768-77.

132. Bohan A, Peter JB. Polymyositis and dermatomyositis (first of two parts). N Engl J Med 1975;292:344-7.

133. Bohan A, Peter JB. Polymyositis and dermatomyositis (second of two parts). N Engl J Med 1975;292:403-7.

134. Sontheimer RD. Would a new name hasten the acceptance of amyopathic dermatomyositis (dermatomyositis sine myositis) as a distinctive subset within the idiopathic inflammatory dermatomyopathies spectrum of clinical illness? J Am Acad Dermatol 2002;46:626-36.

135. Concha JSS, Pena S, Gaffney RG, et al. Developing classification criteria for skin-predominant dermatomyositis: the Delphi process. Br J Dermatol 2020;182:410-7.

136. Sontheimer RD. Cutaneous features of classic dermatomyositis and amyopathic dermatomyositis. Curr Opin Rheumatol 1999;11:475-482.

137. Bendewald MJ, Wetter DA, Li X, et al. Incidence of dermatomyositis and clinically amyopathic dermatomyositis: a population-based study in Olmsted County, Minnesota. Arch Dermatol 2010;146:26-30.

138. Gerami P, Schope JM, McDonald L, et al. A systematic review of adult-onset clinically amyopathic dermatomyositis (dermatomyositis siné myositis): a missing link within the spectrum of the idiopathic inflammatory myopathies. J Am Acad Dermatol 2006;54:597-613.

139. Yang H, Peng Q, Yin L, et al. Identification of multiple cancer-associated myositis-specific autoantibodies in idiopathic inflammatory myopathies: a large longitudinal cohort study. Arthritis Res Ther 2017;19:259.

140. Selva-O'Callaghan A, Trallero-Araguas E, Grau-Junyent JM, et al. Malignancy and myositis: novel autoantibodies and new insights. Curr Opin Rheumatol 2010;22:627-32.

141.Huber AM. Clinical features of myositis: juvenile dermatomyositis. In: Aggarwal R, Oddis CV. editors. Managing myositis: a practical guide. Cham: Springer, 2020:81-9. 
142. Gunawardena H, Wedderburn LR, North J, et al. Clinical associations of autoantibodies to a p155/140 kDa doublet protein in juvenile dermatomyositis. Rheumatology (Oxford) 2008;47:324-8.

143. Gunawardena $H$. The clinical features of myositisassociated autoantibodies: a review. Clin Rev Allergy Immunol 2017;52:45-57.

144. Fiorentino D. Dermatomyositis antibodies continue to mys'TIFy. Br J Dermatol 2019;180:709-10.

145. Mahler M, Vulsteke J, Bossuyt X, et al. Standardisation of myositis-specific antibodies: where are we today? Ann Rheum Dis 2019. [Epub ahead of print].

146. Rönnelid J, Barbasso Helmers S, Storfors H, et al. Use of a commercial line blot assay as a screening test for autoantibodies in inflammatory myopathies. Autoimmun Rev 2009;9:58-61.

147. Ghirardello A, Bendo R, Rampudda ME, et al. Commercial blot assays in the diagnosis of systemic rheumatic diseases. Autoimmun Rev 2009;8:645-9.

148. Ghirardello A, Bettio S, Bassi N, et al. Autoantibody testing in patients with myositis: clinical accuracy of a multiparametric line immunoassay. Clin Exp Rheumatol 2017;35:176-7.

149. Fiorentino DF, Gutierrez-Alamillo L, Hines D, et al. Distinct dermatomyositis populations are detected with different autoantibody assay platforms. Clin Exp Rheumatol 2019;37:1048-51.

150. Mahler M, Fritzler MJ. Detection of myositis-specific antibodies: additional notes. Ann Rheum Dis 2019;78:e45.

151. Cavazzana I, Fredi M, Ceribelli A, et al. Testing for myositis specific autoantibodies: comparison between line blot and immunoprecipitation assays in 57 myositis sera. J Immunol Methods 2016;433:1-5.

152.Espinosa-Ortega F, Holmqvist M, Alexanderson H, et al. Comparison of autoantibody specificities tested by a line blot assay and immunoprecipitation-based algorithm in patients with idiopathic inflammatory myopathies. Ann Rheum Dis 2019;78:858-60.

153. Mahler M, Betteridge Z, Bentow C, et al. Comparison of three immunoassays for the detection of myositis specific antibodies. Front Immunol 2019;10:848.

154. Pinal-Fernandez I, Pak K, Casal-Dominguez M, et al. Validation of anti-Mi2 autoantibody testing by line blot. Autoimmun Rev 2020;19:102425.

155. Mecoli CA, Akbayda J, Tiniakou E, et al. Myositis autoantibodies: a comparison of results from the Oklahoma Medical Research Foundation Myositis Panel to the Euroimmun Research Line Blot. Arthritis Rheumatol
2020;72:192-4.

156. Cavazzana I, Fredi M, Franceschini F. Semiquantitative analysis of line blot assay for myositis-specific and myositis-associated antibodies: a better performance? Ann Rheum Dis 2020;79:e152.

157. Bundell C, Rojana-Udomsart A, Mastaglia F, et al. Diagnostic performance of a commercial immunoblot assay for myositis antibody testing. Pathology 2016;48:363-6.

158. Muro Y, Sugiura K, Akiyama M. A new ELISA for dermatomyositis autoantibodies: rapid introduction of autoantigen cDNA to recombinant assays for autoantibody measurement. Clin Dev Immunol 2013;2013:856815.

159. Fujimoto M, Murakami A, Kurei S, et al. Enzyme-linked immunosorbent assays for detection of anti-transcriptional intermediary factor-1 gamma and anti-Mi-2 autoantibodies in dermatomyositis. J Dermatol Sci 2016;84:272-81.

160. Narang NS, Casciola-Rosen L, Li S, et al. Cutaneous ulceration in dermatomyositis: association with antimelanoma differentiation-associated gene 5 antibodies and interstitial lung disease. Arthritis Care Res (Hoboken) 2015;67:667-72.

161.Femia AN, Vleugels RA, Callen JP. Cutaneous dermatomyositis: an updated review of treatment options and internal associations. Am J Clin Dermatol 2013;14:291-313.

162. Bachmeyer C, Tillie-Leblond I, Lacert A, et al. "Mechanic's hands": a misleading cutaneous sign of the antisynthetase syndrome. Br J Dermatol 2007;156:192-4.

163. Oldroyd A, Sergeant JC, New P, et al. The temporal relationship between cancer and adult onset antitranscriptional intermediary factor 1 antibody-positive dermatomyositis. Rheumatology (Oxford) 2019;58:650-5.

164. Abe Y, Matsushita M, Tada K, et al. Clinical characteristics and change in the antibody titres of patients with antiMDA5 antibody-positive inflammatory myositis. Rheumatology (Oxford) 2017;56:1492-7.

165. Sato S, Kuwana M, Fujita T, et al. Anti-CADM-140/ MDA5 autoantibody titer correlates with disease activity and predicts disease outcome in patients with dermatomyositis and rapidly progressive interstitial lung disease. Mod Rheumatol 2013;23:496-502.

166. Gono T, Sato S, Kawaguchi Y, et al. Anti-MDA5 antibody, ferritin and IL-18 are useful for the evaluation of response to treatment in interstitial lung disease with anti-MDA5 antibody-positive dermatomyositis. Rheumatology (Oxford) 2012;51:1563-70.

167. Aussy A, Fréret M, Gallay L, et al. The IgG2 isotype of anti-transcription intermediary factor- $1 \gamma$ autoantibodies 
is a biomarker of cancer and mortality in adult dermatomyositis. Arthritis Rheumatol 2019;71:1360-70.

168.Zampeli E, Cinoku II, Mavragani CP, et al. Clinical significance of higher cutoffs for myositis autoantibody positivity using the Euroimmun research line blot: comment on the article by Mecoli et al. Arthritis Rheumatol 2020;72:1042-4.

169. Valenzuela A, Chung L, Casciola-Rosen L, et al.

Cite this article as: Hodgkinson LM, Wu TT, Fiorentino DF. Dermatomyositis autoantibodies: how can we maximize utility? Ann Transl Med 2021;9(5):433. doi: 10.21037/atm-20-5175
Identification of clinical features and autoantibodies associated with calcinosis in dermatomyositis. JAMA Dermatol 2014;150:724-9.

170. Tansley SL, Betteridge ZE, Shaddick G, et al. Calcinosis in juvenile dermatomyositis is influenced by both antiNXP2 autoantibody status and age at disease onset. Rheumatology (Oxford) 2014;53:2204-8. 